\title{
Não pode tocar aqui!? Territorialidades sônico-musicais cariocas produzindo tensões e aproximações envolvendo diferentes segmentos sociais
}

\section{Cintia Sanmartin Fernandes, Felipe Costa Trotta e Micael M. Herschmann}

\section{Resumo}

Tomando como base a pesquisa empírica realizada nos últimos dois anos (construída não só a partir da coleta, seleção e análise de matérias veiculadas na mídia impressa tradicional e material postado nas redes sociais, mas também de observações de campo e entrevistas semiestruturadas realizadas com os atores), procura-se refletir sobre os desafios sociais colocados pela música tocada nos espaços híbridos e públicos da cidade do Rio de Janeiro, isto é, busca-se repensar não só quais fatores condicionam os sentidos e significados atribuídos às zonas de contato que são geradas pelas rodas, bailes e concertos executados em certas áreas desta metrópole, mas também de que modo esses eventos musicais - que propiciam articulações e tensões entre atores de diferentes segmentos sociais - vêm, de certa forma, subsidiando no cotidiano a construção de uma cidadania intercultural.

\section{Palavras-Chave}

Comunicação, Música, Cidade, Territorialidades.

\section{Cintia Sanmartin Fernandes}

I cintia@lagoadaconceicao.com

Professora do Programa de Pós-Graduação em Comunicação e Cultura Contemporâneas da Universidade Federal da Bahia - UFBA.

Felipe Costa Trotta I trotta.felipe@gmail.com Pesquisador do CNPq, da Faperj e professor do Departamento de Estudos Culturais e Mídia e do Programa de Pós-Graduação em Comunicação da Universidade Federal Fluminense (UFF). Doutor em Comunicação e Cultura pela UFRJ.

Micael M. Herschmann I micaelmh@globo.com Professor do Programa de Pós-Graduação em Comunicação da UFRJ; Doutor em Comunicação pela UFRJ, com estágios pós-doutorais na Universidade Complutense de Madri e na Pontifícia Universidade Católica de São Paulo.

\section{Introdução}

De modo geral, as pesquisas sobre práticas musicais e espaços urbanos tendem a enfatizar o caráter socializante das experiências sonoras, as quais produziriam "paisagens sonoras" (SCHAFFER 1969), "cenas musicais" (STRAW 1991) e/ou "territórios sônico-musicais" (HERSCHMANN e FERNANDES 2014) pensados como articuladores positivados de identidades e pertencimentos, ações coletivas, compartilhamento de ideias, reforço de laços afetivos e simbólicos. Sem negar a importância de tal perspectiva, mas buscando estender a reflexão sobre as práticas musicais cotidianas, procura-se neste texto isolar dois casos nos quais a experiência musical pode ser objeto de conflitos e disputas.

Para além de uma postura "politicamente correta", como se posicionar em relação às matérias jornalísticas (ver abaixo) que vem tomando conta do noticiário do Rio de Janeiro com um tom nitidamente mais legalista e/ou conservador?

(...) Primeiro foi 0 chorinho. Depois, o samba. Logo chegaram também a música dos Bálcãs, o maracatu, o jazz, o rock, a feirinha, os 
malabaristas, os poetas e os cineastas (...). Entre o coreto e 0 chafariz, a efervescência cultural mudou a cara da velha pracinha. (...) Gus The Fus, baixista da banda Beach Combers, recorda de situações boas e ruins que ocorreram nas ocasiões que o grupo foi tocar lá. Não só o trabalho da banda já foi tanto muito aplaudido pelo público e os comerciantes e ambulantes do lugar já os convidaram a se apresentar de novo lá, mas também já aconteceu de serem impedidos de tocar pela Guarda Municipal. (...) Era cedo, mas alguns moradores reclamaram da altura do som e que os músicos tocavam plugados (...). A secretaria de Segurança não soube informar precisamente quantas reclamações foram feitas ao telefone 190 por causa do barulho nos últimos meses (...). A secretaria de Ordem Pública informou, em nota, que a Praça São Salvador está incluída no roteiro de fiscalização e patruIhamento da Guarda Municipal, em horários aleatórios. Segundo o órgão, as ações estão sendo intensificadas no local'.

Nota-se que, frequentemente, os meios de comunicação e alguns estudos colocam em pauta a seguinte discussão: a experiência musical aproxima e/ou afasta os indivíduos em determinados contextos? Constrói pontes e/ou amplia o preconceito social em mundo tão instável e complexo? Claro que sempre se pode afirmar que os concertos musicais realizados nos espaços públicos ou mesmo em localidades híbridas (nos quais os sons vazam pelo território, tais como clubes e quadras poliesportivas de associações de morros e favelas) geram ambos os tipos de fenômenos. Entretanto, isso talvez explique muito pouco quais são os vetores decisivos que levam a se atribuir prioritariamente certos sentidos e significados a diferentes situações. Poder-se-ia indagar: 0 que leva os atores a considerar certas iniciativas musicais como expressões artísticas/culturais mais ou menos legítimas e/ou relevantes e outras não? Por que outras práticas musicais são consideradas como ruído, inadequadas, ilegítimas e/ou perturbadoras da ordem? Evidentemente, estas questões podem ser problematizadas da perspectiva legal, dos direitos dos cidadãos e serão brevemente discutidas aqui mais à frente (no item 4) neste artigo.

Há outros aspectos que devem ser levados em conta e que sublinham a relevância sociopolítica deste tipo de debate para a população da cidade do Rio de Janeiro. A capital carioca parece oscilar entre 0 imaginário de uma cidade considerada "maravilhosa" e "partida" (VENTURA, 1994; VELHO e ALVITO, 1996). A força destes sentidos no imaginário social com alguma frequência é discutida; contudo, a "violência da estrutura social" (MAFFESOLI, 1987) presente nos processos urbanísticos em curso é sensivelmente menos debatida. Ferreira (2014), um dos críticos do projeto em curso no país e especialmente no Rio, faz os seguintes comentários, quase em tom de denúncia:

Foi um governo socialista, do francês Mitterand, que inaugurou o que se tornaria a "solução" (...). A ideia difundida era a de que gastos concentrados - muito menores do que políticas sociais em grande escala - gerariam uma "imagem positiva" da cidade, capaz de atrair os fluxos do novo capital financeiro. (...) Nos anos 1990, a receita espalhou-se pelo mundo 
(...). Multiplicam as obras simbólicas, assinadas por grandes arquitetos, emergentes de um novo jet set internacional da profissão. (...) Porém, nem sempre as "requalificações de bairros obsoletos" com dinheiro público tiveram a aceitação esperada, apesar do selo "cultural". Na crise econômica, a estratégia de comprometer recursos foi negativamente cotejada com a redução de investimentos em políticas sociais. (...) Era necessário legitimar esse modelo de alguma forma. Percebeu-se então que grandes eventos, sobretudo os esportivos, que movem paixões nacionais, tinham a grande "qualidade" de serem popularmente aceitos. A ideia era associar esses eventos às obras de requalificação urbana desejadas. (...) 0 tsunami de capitais envolvidos vem aprofundando a dinâmica estrutural de desigualdade urbana e segregação socioeconômica. Junto a estádios, ginásios e pavilhões, estruturam-se equipamentos, empreendimentos comerciais, bairros de negócios e são construídas importantes vias de acesso que interessam especialmente aos organizadores e raramente são prioritárias para a cidade (FERREIRA, 2014, p. 5-7).

Neste sentido, alguns atores e intelectuais vêm questionando a ideia de que as intervenções urbanas em andamento deixarão legados sociais importantes. É possível afirmar que se assiste a um momento especial da democracia brasileira, de explosão das manifestações de rua e de muito debate em torno das mesmas. Com certeza, é um momento importante de amadurecimento de uma democracia que começa a ganhar maior densidade, especialmente com as reformas sociais implementadas nas últimas décadas e pela emergência da chamada "nova classe média" ou "classe $\mathrm{C}$ ". Vale salientar que este artigo colocará a ênfase nas tensões e nos conflitos entre os atores; no entanto, já assinalamos em outros trabalhos elaborados anteriormente a grande capacidade da música em mobilizar diferentes segmentos sociais, construindo "pontes" entre atores de diferentes segmentos sociais (HERSCHMANN e FERNANDES, 2012 e 2014).

Portanto, o objetivo deste trabalho é refletir sobre os desafios sociais colocados pela música tocada nos espaços híbridos ${ }^{3}$ e públicos da cidade, isto é, busca-se repensar não só quais fatores condicionam os sentidos que são atribuídos às "zonas de contato" que são geradas pelas

Para alguns economistas e sociólogos, o termo é bastante frágil, impreciso e não dá conta de explicar a realidade vivida por uma classe trabalhadora precarizada. Para outros, 0 aumento da renda do segmento pobre da população está criando um novo segmento de consumidores, 0 qual vem obrigando as empresas a se adaptarem a uma crescente demanda. Para mais informações, ver: NERl et al., 2008.

Entre os espaços privados e os públicos, criam-se "zonas" configuradas como "híbridas", onde a fusão entre interior e exterior se dá pela instalação de equipamentos internos na área externa, ou pelo tipo de ocupação social destes espaços (REIS, 2013). Emprega-se aqui esta noção para explicar o debate público, o qual é frequentemente travado, envolvendo os bailes funk, que são realizados de modo geral em: clubes e/ou quadras poliesportivas de associação de moradores, localizadas, na sua maioria, nas periferias e favelas da cidade. Por um lado, as tensões com a vizinhança estão relacionadas aos sons que vazam destes locais e são interpretados como "ruído"; e, por outro, outra questão recorrente envolve a circulação dos grupos que vão para as festas (que "zoam pelo Rio") e que produz conflitos ou que, muitas vezes, intimida outros indivíduos e grupos. 0 mesmo acontece com os rolezinhos que são realizados em shoppings (TROTTA, 2014). Portanto, os bailes funk da cidade ocorrem em espaços hibridos que lançam desafios e questões que, claramente, são da esfera pública.

Inspirando-se no trabalho de Pratt, o antropólogo James Clifford, em seu artigo "Museums as contact zones" (1997), considera as "zonas de contato" como espaços que estabelecem condições de copresença e interação entre os atores, contudo quase sempre dentro de relações assimétricas de poder. 
rodas, bailes e concertos executados em certas áreas desta metrópole, mas também em que medida esses eventos musicais - os quais propiciam articulações e tensões entre atores de diferentes estratos sociais - vêm, de certa forma, subsidiando no cotidiano a construção de uma "cidadania intercultural" (GARCIA CANCLINI, 2011). Assim sendo, parte-se do pressuposto de que a música tocada nas ruas da cidade e os bailes de comunidade são estudos de caso significativos para se repensar o papel da música na transformação da "paisagem sonora" (SCHAFER, 1969) e na construção de "territorialidades sônico-musicais" ${ }^{2}$, que alteram a relação dos atores com seu cotidiano neste território.

Evidentemente, há um conjunto de reflexões que vem sendo desenvolvido pela literatura que trabalha com a ecologia sonora ou que está filiado aos Sound Studies, a partir dos quais os especialistas tentam também compreender aspectos conformadores das espacialidades (SCHAFER, 1969; LABELLE, 2010; KITTLER, 1999; CONNOR, 2000). Como será possível atestar neste trabalho, parte-se do pressuposto de que há os aspectos socioculturais que dão mais conta de explicar por que os sons são aceitos ou não em determinados territórios e ocasiões, isto é, para além da paisagem sonora, das diferenças entre os segmentos sociais, da aplicação de leis e dos interesses dos atores, é preciso também levar em consideração outros vetores que problematizaremos neste trabalho.

\section{Além de choro e samba, o que pode rolar na Praça?}

De modo geral, a Praça São Salvador, no bairro de Laranjeiras, é reconhecida pela população carioca como a "Praça do Choro e do Samba". Esses gêneros musicais apropriaram-se desta localidade por volta de 2007 no momento em que a Associação de Moradores local - segundo os atores, "farta de descaso dos órgãos competentes da prefeitura" - decidiu ocupar o espaço mal cuidado e pouco aproveitado. Essa ocupação do choro, aos sábados, produziu uma territorialidade sônico-musical específica, que circula com força no imaginário da população da cidade e que permanece sendo reiterada a partir de um "contrato sônico-musical" entre alguns moradores com bases em valores musicais tradicionais ${ }^{6}$.

A força desse imaginário gerou desdobramentos ao longo dos anos, e uma parcela dos moradores - representados pela Associação de Moradores

Com esta noção "territorialidades sônico-musicais", busca-se valorizar a importância da música e das inúmeras sonoridades presentes no cotidiano das cidades para os processos de reterritorialização que serão realizados pelos atores pesquisados. Muitas vezes, a decisão da área que será ocupada com concertos de música leva em conta não só a circulação dos atores, mas também o fluxo e a intensidade dos fluxos sônicos presentes no local (HERSCHMANN e FERNANDES, 2012).

6 Conferir o curta-metragem "Viva a Praça São Salvador", produzido por Aline Macedo, Homero Zapponi e Marina Brandão para a disciplina Comunicação e Cultura II, lecionada pela professora Cíntia Sanmartin Fernandes (em 2012) do curso de Jornalismo da Faculdade de Comunicação Social (FCS), da Universidade do Estado do Rio de Janeiro (UERJ). Agradece-se a Aline Macedo (bolsista de IC) por ter cedido o material de pesquisa para elaboração deste trabalho. 
- abriu caminho para que, posteriormente, se diversificasse a experiência musical do local. Às quintas e sextas se passou a convidar grupos de jazz, rock e blues que atraíram um público mais jovem para este espaço. Conforme ressalta 0 presidente da Associação de Moradores da região:

(...) resolvi ocupar a praça, aliás, nossa sociedade deveria ocupar todas as praças. Contratei uma banda numa sexta-feira, paguei, contratei na outra sexta-feira. Na terceira vez já não precisei pagar nada, pois já tinha gente que aparecia querendo tocar (...). Surgiu uma juventude cheia de talento querendo tocar (...) o resultado é isso que você está vendo acontecer (...). Claro que nada vai agradar a todos! É natural que você tenha uma parcela da população (...) que realmente se incomodam, mesmo antes do horário das 22 horas. (...) Nós temos que ser tolerantes e conviver com isso porque é uma programação cultural ofertada a todos gratuitamente ${ }^{7}$.

A partir de 2013, esta tradicional "Praça do Choro e do Samba" foi convertida também em espaço do jazz, do rock, do samba e do maracatu. Com uma oferta musical de quinta a domingo, a juventude das cercanias e de outros bairros da cidade começou a desfrutar da diversidade cultural do espaço. Houve uma transformação na paisagem sonora e configuração de outras territorialidades sônico-musicais, as quais passaram a se fazer presentes neste espaço. Neste sentido, Garnizé traça o seguinte comentário:
Acho que 0 que fez mudar mesmo esta localidade foi essa juventude, que está aqui vindo revitalizar isso aqui... dar uma cara nova para um uso arcaico deste espaço. Esta praça estava jogada às traças. A verdade é que 0 poder público não dava nenhuma atenção. Comparo esta praça hoje com as praias da cidade (...). Aqui tem preto, branco, lésbica, homossexual, skatista, rico, pobre, tem de tudo aqui (...). Acho que esta praça aqui é a cara do Rio8.

No entanto, a introdução de novos ritmos e sons trazidos por outros grupos começou a exigir uma negociação mais intensa e complexa. Foi possível constatar neste estudo de caso que as mudanças nem sempre são bem aceitas pelos grupos estabelecidos, os quais acionam um repertório de narrativas que pregam a obstrução da diversidade em nome da "tradição" (HOBSBAWM e RANGER, 1985) e preservação de uma memória sônico-musical. Independentemente de horário, gênero musical ou classe social, por vezes, esses grupos - dispostos a proibir, por exemplo, que gêneros musicais como 0 rock ou maracatu ocupem a área - aliam-se não só aos interesses dos moradores descontentes com 0 "barulho" da praça, mas também ao poder público, 0 qual emprega mecanismos coercitivos e normativos que se popularizaram na cena midiática, como a expressão "choque de ordem".

Sobre essa tensão $0^{9}$, Garnizé, músico e professor da Escola Maracatu Brasil, relata:

Entrevista concedida por Agostinho dos Santos, presidente da Associação dos Moradores da localidade, para a pesquisa desenvolvida por Aline Macedo, em 08 de outubro de 2013.

8 Entrevista concedida por Alexandre Garnizé, músico e professor da Escola Maracatu Brasil, para a pesquisa desenvolvida por Aline Macedo, em 10 de setembro de 2013.

Há diversos vídeos sobre a ação do choque de ordem na Praça São Salvador (disponível em: <https://www.youtube.com/ watch?v=vE5n2ufTG6o>, último acesso: 21/01/2015). 
Como é possível proibir que alguma coisa aconteça em praças públicas? Como é possível proibir a dança, proibir a música, proibir alguém de se expressar? (...) A música de rua está crescendo na São Salvador e isso virou uma justificativa para que alguns moradores reclamem e a polícia obstrua 0 acesso à cultura. Olha, se você olhar com cuidado vai constatar que a Secretaria de Ordem Pública não sai daqui, temos policiais circulando direto ${ }^{10}$.

Para alguns músicos, artistas e frequentadores, as tensões vêm se intensificando no último ano. Alguns sugerem que, após as manifestações de junho de 2013 e a Copa do Mundo em 2014, houve um significativo aumento do policiamento e das práticas coercitivas na localidade e, de modo geral, na cidade.

\begin{abstract}
(...) Aparentemente, a repressão está mais institucionalizada desde 0 final de 2013 (...). Não sei se tem também uma relação com a Copa e as manifestações que têm sido centralizadas aqui em Laranjeiras (perto do Palácio do Governo). 0 fato é que as autoridades têm mobilizado esse aparato da Secretaria de Ordem Pública (...). Venho aqui há uns dois anos. Eu peguei um período em que a Maracatu Brasil ainda tinha mais tranquilidade para tocar e fazer as apresentações. $\mathrm{Ou}$ seja, vi essas manifestações transcorrerem de uma forma mais livre, e comecei a observar também essas atitudes mais repressoras. Muitas vezes, os artistas passaram a ser impedidos de tocar, apesar de não fazer tanta diferença assim - do ponto de vista sonoro - para a vizinhança ${ }^{11}$.
\end{abstract}

Para os entrevistados, essa "aliança" entre parte dos moradores (que querem o silêncio e a volta da "praça pacata") e a administração pública tenta interromper o dinamismo produzido pelos encontros musicais no local, isto é, conter um pouco o "potencial movente da música" (HERSCHMANN, FERNANDES, 2012), o qual aciona diversas sociabilidades neste espaço. Ao longo do ano de 2014, o que se pode notar é que, com as medidas coercitivas que vêm sendo adotadas pelo Estado, a Praça perdeu parte do seu dinamismo. Apesar dos esforços de parte das lideranças locais que seguem tentando realizar concertos de jazz, rock e maracatu, as atividades musicais estão praticamente restritas ao final de semana e aos gêneros musicais - choro e samba -, associados às territorialidades sônico-musicais que já estavam estabelecidas (antes desta praça ganhar notoriedade na cidade como um "lugar" da boemia carioca).

Vale enfatizar que este estudo de caso é significativo porque indica que os processos de introdução de novos ritmos e sons nem sempre são tranquilos. Quando há uma territorialidade sônico-musical existente (uma tradição musical do lugar), nem sempre é simples negociar mudanças no território: independentemente do horário de silêncio, do gênero musical e da classe social de quem protagoniza as iniciativas. Com frequência,

10 Entrevista concedida por Alexandre Garnizé, músico e professor da Escola Maracatu Brasil, para a pesquisa desenvolvida por Aline Macedo, em 10 de setembro de 2013.

11 Entrevista concedida por Natália Santos, musicista e mestranda de Sociologia da UFRJ, para a pesquisa desenvolvida por Aline Macedo, em 10 de setembro de 2013. 
depende também da tolerância dos atores em compartilhar o território, em permitir que outras territorialidades sônico-musicais se sobreponham na localidade. Em razão disso, muitas vezes os músicos que tocam nas ruas - como estratégia alternativa - vão buscar áreas "esvaziadas" da urbe, as quais não possuem "contratos sônicomusicais" prévios e/ou solidamente estabelecidos.

\section{0 caso do funk}

Quando falamos em ocupação das ruas com música e de conflitos relacionados a práticas musicais executadas em locais públicos no Rio de Janeiro, é inevitável lembrarmos do funk. 0 funk talvez seja o gênero que tenha protagonizado, nas últimas décadas, os mais inflamados tensionamentos e debates sobre a ocupação musical da cidade. Cercado de uma série de estereótipos negativos associados à sua origem social e geográfica periférica, o funk tem sido alvo de diversas ações e enfrentamentos que, não raramente, tornam-se caso de polícia.

A história do funk no Rio de Janeiro é permeada por dois processos de estigmatização. De um lado, é possível observar um protagonismo da imprensa brasileira que, há mais de 20 anos, produz um conjunto de discursos sobre o funk que o associa fortemente ao mundo da criminalidade e do tráfico de drogas. As notícias veiculadas pelos jornais sobre um arrastão na Praia de Ipanema em 1992 são reconhecidas como marcos críticos dessa narrativa, que, paradoxalmente, contribuíram para a divulgação e glamourização do funk no imaginário carioca e nacional (HERSCHMANN, 2000). A partir desse universo de ideias e recriminações, a polícia e o Poder Judiciário têm protagonizado apreensões, interdições e até mesmo prisões de artistas do funk, sob a alegação de suspeita de crime de "apologia"12. Em instigante análise sobre a criminalização do funk, o jurista Nilo Batista aponta que a figura jurídica penal da "apologia" - da forma como vem sendo aplicada contra os cantores de funk e os próprios bailes - é frontalmente contraditória com a liberdade da criação artística e de manifestação do pensamento expressa redundantemente em diversos artigos da Constituição. Para 0 autor, há um enorme risco em "arrogar-se o juiz do poder de determinar se a manifestação artística criminalizada constitui ou não obra de arte" (BATISTA, 2013, p. 202).

Apesar do debate judicial, as tentativas de limitar os bailes funk são continuamente realizadas pelas forças de segurança pública. A partir da instalação das Unidades de Polícia Pacificadora (UPP) nas favelas da cidade do Rio de Janeiro, em 2008, circulam diversas notícias sobre a 
proibição dos bailes nas localidades "pacificadas" como estratégia para "manter a ordem". Assim, para proibir a realização dos bailes, as UPPs usualmente apoiam-se em uma resolução da Secretaria de Segurança do Estado do ano anterior (conhecida como "Resolução n ${ }^{0}$ 13"), a qual conferia à Polícia Militar o poder de "autorizar ou não - qualquer tipo de evento cultural" (ENNE e GOMES, 2013, p. 56). É evidente que o veto aos bailes produziu reações de grupos comunitários, de políticos mais progressistas e associações culturais locais. Mas as dificuldades de realização dos bailes permanecem e têm sido consideradas estratégicas pelas UPPs para "manter a ordem". Cinco anos depois de iniciado o processo controverso de "pacificação" das favelas cariocas, não deixa de causar surpresa a reportagem do Jornal $O$ Dia, na qual o secretário estadual de Segurança, José Mariano Beltrame, garante que os bailes funk serão legalizados.

0 baile funk nas comunidades vai ser legalizado até 0 fim de 2013. Sem alarde, a Secretaria de Segurança entregou à Casa Civil, em abril, um estudo pedindo a flexibilização da Resolução $n^{0}$ 13, que prevê uma série de pré-requisitos para a realização de eventos, tanto nas favelas quanto no asfalto. 0 tema vem avançando e 0 grupo de estudo que trabalha no assunto deve entregar suas conclusões até setembro ${ }^{13}$.

0 texto da matéria evidencia que há uma notória conexão entre bailes e criminalidade na visão dos representantes da segurança pública no Estado. 0 coronel Paulo Henrique, então coordenador das
UPPs, ouvido pelo repórter, salienta que a imagem do baile ainda é muito ligada ao tráfico e que isso "tem que mudar aos poucos, isto é, é preciso ter cuidado com a repercussão da liberação para não dizerem que a bagunça voltou". A associação do baile com a ideia de "bagunça" (vocábulo elástico que pode se referir ao comércio do tráfico, às drogas em si, à tortura, à festa, a atos sexuais, e a uma ideia difusa de desorganização) é um exemplo desse amplo processo de condenação do funk e de limitação de sua circulação pela cidade.

De todo modo, a intenção de Beltrame parece não ter se concretizado pelo menos até janeiro de 2014, quando 0 baile que seria realizado na boate Emoções, na Rocinha, foi impedido pela comandante da UPP local, conhecida como major Priscila. Após um ano e meio fechada para conseguir adequação burocrática (possivelmente tentando cumprir as exigências da temida Resolução $\mathrm{n}^{0} 13$ ), a casa de espetáculos havia obtido, finalmente, os documentos e as autorizações da Prefeitura e do Corpo de Bombeiros para a organização de festas. Nos dias 12 e 19 de janeiro, a boate promoveu os primeiros bailes, mas a festa seguinte, marcada para o dia 26, não ocorreu porque a polícia suspendeu a licença.

Em matéria no dia 11 de fevereiro, O Dia narra a história e fornece um detalhe interessante: um baile de forró havia sido realizado no sábado anterior, mas o funk permanecia proibido. 0 
presidente da Associação dos Profissionais e Amigos do Funk (Apafunk), Mano Teko, declarou à época que a tolerância em relação ao baile de forró expunha o preconceito da major Priscila com o funk e caracterizava a interdição como um caso de discriminação. Discriminação essa que não se restringe apenas à capital carioca, mas que acompanha 0 funk em todas as cidades brasileiras.

Na época da proibição na Rocinha, as notícias sobre os "rolezinhos" obtinham destaque em todo o país, sempre estabelecendo alguma relação entre a "ocupação" dos shoppings e o funk (TROTTA 2014). Em alguns casos, as matérias jornalísticas veiculadas sugeriam que a proibição dos bailes funk era um dos principais motivos para a convocação dos rolezinhos em São Paulo. De alguma forma, a atividade cultural do funk continua a ser entendida como problemática pelos órgãos de fiscalização e policiamento do Estado.

Porém, por outro lado, é possível identificar diversos atores sociais que vêm construindo tensões e disputas, os quais visam denunciar e contestar as decisões arbitrárias do Estado. Políticos ligados a determinados partidos e associações de profissionais e de moradores configuram-se como grupos de pressão que acionam publicamente (e, muitas vezes, judicialmente) os órgãos de segurança pública e produzem um embate concreto. Nesse cenário, merece destaque a atuação da Apafunk, entidade que agrega profissionais do funk e que promove debates, bailes e diversas atividades que têm como objetivo deslocar o imaginário negativo associado a este gênero musical. A atuação desta associação junto ao Estado tem conseguido problematizar alguns casos e reverter decisões autoritárias de interdição. 0 caso da major Priscila é exatamente um deles. Após a matéria d'O Dia, agentes do Estado e da sociedade se mobilizaram e, já no dia seguinte, 12 de fevereiro, o comando da UPP da Rocinha "autorizou" o baile. Constatou-se uma curiosa manobra política, linguística, policial e judiciária que autorizou - via imprensa - o que os documentos e alvarás afirmavam já estar autorizado.

A atuação desses grupos sociais tem a função política de levantar o debate e publicizá-lo, convocando a sociedade e seus representantes legais (nos parlamentos e na Justiça) a alterar 0 modus operandi explicitamente discriminatório, 0 qual reprime não só o funk, mas também a música de rua no Rio de Janeiro. Como se pode atestar nos dois estudos de caso analisados, a formulação de leis emerge nessas polêmicas como tentativas de regular e proteger estas práticas culturais da truculência e intransigência dos setores mais conservadores da sociedade, que, recorrentemente nos media, "clamam pela ordem social", isto é, por intervenções do aparato policial no cotidiano.

\section{A função e 0 que dizem as leis}

As leis em vigor na cidade do Rio de Janeiro (e que abrangem os dois estudos de caso analisados 
aqui) se posicionam aparentemente de forma clara sobre a temática, determinando um conjunto de procedimentos que devem ser realizados antes de se autorizar ou reprimir as iniciativas musicais nestes espaços públicos ou híbridos.

No caso dos concertos musicais executados nos espaços públicos, a "Lei do Artista de Rua"14 é uma referência fundamental para as polêmicas envolvendo os atores. De acordo com o texto, "as manifestações culturais de Artistas de Rua no espaço público aberto, tais como praças, anfiteatros, largos, bulevares, independem de prévia autorização dos órgãos públicos municipais". De certa forma, a lei apresenta uma visão oposta à Resolução $\mathrm{n}^{0} 13$ da Polícia Militar, ao liberar a burocracia para as apresentações de rua, desde que ressalvadas algumas garantias, como livre circulação, limite de horário e que as apresentações sejam gratuitas e sem patrocinadores. Recorrentemente, os músicos afirmam: "esta lei municipal foi uma conquista muito importante, apesar de frequentemente não ser respeitada"15. Portanto, a Lei do Artista de Rua, aprovada em 2012, é mencionada amplamente no trabalho de campo pelos atores como um marco significativo na história cultural da cidade do Rio de Janeiro. Segundo Amir Haddad, reconhecida liderança da cena teatral e cultural carioca, que atuou de forma destacada na negociação e aprovação desta lei:

A aprovação desta lei abre caminho para a construção de uma cidade mais democrática, com possibilidades de construir mais inclusão social, na qual pode haver mais acesso à cultura para todos. (...) Portanto, não foi fácil negociar esta lei, inclusive a prefeitura voltou atrás e demonstrou sensibilidade, percebendo que a arte pública, que ocupa as praças e ruas, é uma riqueza desta cidade, que faz do Rio uma cidade especial. Há uma vida cultural importante que acontece nos espaços públicos desta cidade. (...) Levamos fortes argumentos à prefeitura $\mathrm{e}$ conseguimos abrir novas perspectivas, mais democráticas para a cidade, num momento em que ela se globaliza e que há, infelizmente, um processo de encarecimento do custo de vida e de exclusão social significativo ${ }^{16}$.

É possível constatar a partir do depoimento anterior que, se, por um lado, o poder público adota, muitas vezes, uma postura repressiva e autoritária, sintetizada nas iniciativas de "choque de ordem" muito empregadas nos últimos anos em várias localidades do Rio de Janeiro, por outro lado, há um entendimento (ou existe certa "sensibilidade" ou percepção por parte dos setores progressistas que atuam no Estado) de que a produção cultural que ocupa os espaços públicos pode ser capitalizada para reconstruir ou atualizar, no imaginário social, a imagem da Cidade Maravilhosa,

14 A lei municipal n 5429 (de 05 de junho de 2012) regulamenta apresentação de artistas de rua nos logradouros públicos do município do Rio de Janeiro. Esta lei desburocratiza o processo de uso dos espaços públicos, acabando com a exigência prévia de os artistas conseguirem permissões junto aos órgãos públicos para se apresentarem nesse tipo de espaço.

15 Entrevista com Miguel Maron, percussionista do grupo Os Siderais, concedida à nossa pesquisa no dia 11 de julho de 2014.

16 Entrevista com Amir Haddad, liderança do grupo Tá na Rua e do Movimento Arte Pública, concedida à nossa pesquisa no dia 25 de junho de 2014. 
capaz de atrair investimentos, turistas, isto é, que a cultura pode ser empregada como "recurso" (YÚDICE, 2005) para alavancar o desenvolvimento desta metrópole.

Nessa linha de ação, inserem-se os discursos acerca da chamada Lei do Funk (Lei Estadual $\mathrm{n}^{0} 5543$, de 22/09/2009), os quais culminam na afirmação recorrente de que "funk é cultura". "0 enunciado 'funk é cultura' cita e rompe com a cadeia significante que coloca no mesmo eixo paradigmático os termos favela, favelado, tráfico, traficante, funkeiro, funk, coisa de bandido" (LOPES, 2011, p. 87). 0 texto da lei é uma peça retórica que fala sobre essa tensão entre a ideia de funk como prática cultural legítima e a violenta repressão estigmatizadora processada pela imprensa, pela política e pelo Poder Judiciário no cotidiano da cidade. Seu enunciado afirma no artigo 1 que 0 funk "fica definido" como "movimento cultural e musical de caráter popular”, mas, no primeiro parágrafo do mesmo artigo, exclui da "regra" "conteúdos que façam apologia ao crime" (artigo $1^{\circ}$, parágrafo único). A vaga noção de apologia deixa brechas para ações de repressão, mas pauta uma estratégia de separação entre o funk que é permitido e aquele que é proibido. Os outros artigos da lei reafirmam o caráter cultural do funk, determinando que os "assuntos relativos ao funk deverão, prioritariamente, ser tratados pelos órgãos do Estado relacionados à cultura" (artigo $3^{\circ}$, grifo nosso), os artistas devem ser respeitados (artigo $5^{0}$ ) e proibindo a discriminação e o preconceito contra 0 funk (artigo $4^{\circ}$ ).

Na votação que aprovou na Assembleia Legislativa do Rio de Janeiro a referida lei, o antropólogo Hermano Vianna disse não conhecer "registro de repressão tão violenta contra qualquer outra manifestação cultural festiva de qualquer outro lugar do mundo" ${ }^{17}$. Ainda que se possa identificar certo exagero nas afirmações de Vianna, a noção de uma historicidade repressiva contra 0 gênero perpassou outras falas da sessão, como da pesquisadora Adriana Facina, que reiterava que "a discriminação contra o funk é mais um capítulo de uma longa história de criminalização da cultura negra no Brasil" (LOPES, 2011, p. 69). Nesse terreno de disputas simbólicas e discursivas, os artistas e fãs de funk concordam que a promulgação da lei é uma peça importante no processo de descriminalização da prática do gênero na cidade, funcionando como um contraponto a decisões que inibem a realização das festas e de bailes. Mas (como se pode constatar nos depoimentos dos atores), o papel da letra escrita da lei nem sempre é capaz de dissolver construções simbólicas longevas.

Poder-se-ia afirmar o mesmo sobre os artistas de rua, os quais convivem cotidianamente com riscos de repressão e incompreensão que navegam em outras peças legais e normas de conduta. Como 
salientaram vários grupos de música que ocupam os espaços públicos de forma menos negociada, a Lei do Artista de Rua nem sempre é respeitada pelas forças de segurança.

\begin{abstract}
A Lei do Artista de Rua foi importante e acho que os grupos musicais que tocam nas ruas do Rio aumentaram. Quando o nosso grupo começou a tocar na cidade no início desta década, quase não havia artistas de rua. Claro que a situação melhorou muito e o crescimento dos grupos é uma prova disso (...). Mas os policiais nem sempre respeitam a lei e ficam exigindo muita papelada. A gente sempre explica que, com a nova lei, caducou uma série de exigências para tocar, mas os caras ficam insistindo e às vezes, mesmo com a receptividade do público, temos que desistir de tocar num determinado lugar ${ }^{18}$.
\end{abstract}

Assim, tendo em vista os comentários dos atores (e as observações de campo realizadas), apesar das leis aparentemente serem claras, há situações em que os shows e as rodas são permitidos e/ou tolerados e, em outras vezes, os direitos dos artistas - apesar de estarem atuando rigorosamente dentro da lei - é que não são respeitados, e sua atividade é interditada pelos órgãos de segurança pública.

\section{Considerações Finais}

Analisando a história da cidade do Rio de Janeiro, é possível verificar que há uma longa tradição de ocupação das áreas públicas e híbridas da cidade (HERSCHMANN e FERNANDES, 2014): existe uma farta literatura que enfatiza a presença de rodas, bailes, concertos e festas de todo tipo que ocupam as ruas da cidade (TINHORÃO, 1978; MOURA, 1983). Poder-se-ia afirmar que 0 Rio de Janeiro é uma "cidade musical", que tem uma "cultura de rua" intensa (HERSCHMANN e FERNANDES, 2012 e 2014) e é considerado um importante centro de produção da música nacional (HERSCHMANN, 2010). Entretanto, de alguns anos para cá - com a efetivação do projeto de construção de uma "cidade global" -, percebese que há a presença dos modus operandi dos aparatos de ordem pública, os quais buscam desestimular a ocupação dos espaços públicos e híbridos da cidade, especialmente se os eventos musicais (e culturais) não interessam ao grande capital. As recorrentes tensões entre os atores (músicos e frequentadores) e membros das forças de segurança pública indicam, claramente, como as questões debatidas neste artigo são relevantes na história recente desta metrópole.

Tendo em vista tudo que foi assinalado aqui, é possível argumentar que a música tocada nas ruas e em espaços híbridos desta cidade vem colaborando - através das práticas e dos discursos que possibilitam a emergência de debates e imaginários sociais - para a construção, em alguma medida, de uma "cidadania intercultural" (GARCIA CANCLINI, 2011) neste território estudado, o qual é caracterizado (apesar dos avanços nas áreas sociais) por significativas desigualdades e tensões sociais. 


\section{Referências}

BATISTA, Nilo. Sobre a criminalização do funk carioca. In: BATISTA, Carlos B. (org.). Tamborzão. Rio de Janeiro: Revan, 2013.

BORGES, Rafael. A produção legislativa em torno das “apologias”. In: BATISTA, Carlos B. (org.). Tamborzão. Rio de Janeiro: Revan, 2013.

CLIFFORD, James. Routes. Massachusetts, Havard University Press, 1997.

CONNOR, Steven. Dumbstruck. Oxford: Oxford University Press, 2000.

ENNE, Ana L.; GOMES, Mariana. É tudo nosso. In: PASSOS, Pamela et al. (orgs.). Política cultural com as periferias. Rio de Janeiro: IFRJ, 2013.

FERREIRA, João Sette W. Apresentação: um teatro milionário. In: JENNINGS, Andrew et al. (Orgs.).

Brasil em jogo. São Paulo: Boitempo, 2014.

GARCÍA CANCLINI, Néstor G. (org.) Conflictos

interculturales. Barcelona: Gedisa, 2011.

HERSCHMANN, Micael. 0 funk e o hip hop invadem a cena. Rio de Janeiro: Ed. UFRJ, 2000.

\section{Indústria da Música em Transição. São}

Paulo: Estação das Letras e das Cores, 2010.

HERSCHMANN, Micael; FERNANDES, Cíntia S.

Potencial movente do espetáculo, da música e da espacialidade no Rio de Janeiro. In: RIBEIR0, Ana P. G.; FREIRE FILHO, João; HERSCHMANN, Micael. (Orgs.) Entretenimento, felicidade e memória. Rio de Janeiro: Anadarco, 2012. ; Música nas ruas do Rio de

Janeiro. São Paulo: Ed. Intercom, 2014.

HOBSBAWM, Eric; RANGER, Terence. A invenção das tradições. Rio de Janeiro: Paz e Terra, 1985.

KITTLER, F. Gramophone, Film, Typewriter. Stanford: Stanford University Press, 1999.
LABELLE, Brandon. Acoustic Territories. Nova York: Continuum, 2010.

LOPES, Adriana C. Funk-se quem quiser.

Rio de Janeiro: Bom Texto, 2011.

MAFFESOLI, Michel. A dinâmica da violência. São Paulo, Vértice, 1987.

MOURA, Roberto. Tia Ciata e a pequena África do

Rio de Janeiro. Rio de Janeiro: FUNARTE, 1983.

NERI, Marcelo Cortes et al. A nova classe média. Rio de Janeiro: FGV/IBRE/CPS, 2008.

REIS, Vanessa. Urbanidade no espaço privado. In: Anais da III ENANPARQ. São Paulo: ENANPARQ, 2014.

SCHAFER, Raymond M. The new soundscape. Vancouver: Don Mills, 1969.

STRAW, Will. Systems of articulation, logics of change. In: Cultural Studies, v. 5 n. 3, New York: Routledge, 1991.

TINHORÃO, José Ramos. Pequena História da Música Popular. São Paulo: Ática, 1978.

TROTTA, Felipe. A música que incomoda: o funk e o rolezinho. In: Anais da XXIII Compós. Belém: COMPÓs, 2014.

VELHO, Gilberto e ALVITO, Marcos (orgs.). Cidadania e violência. Rio de Janeiro, Ed. UFRJ, 1996.

VENTURA, Zuenir. A Cidade partida. São Paulo, Cia. das Letras, 1994.

YÚDICE, George. A conveniência da cultura. Belo Horizonte: Ed. UFMG, 2005. 


\section{You can't play here!? Sonic- musical territorialities in Rio de Janeiro producing strains and approaches involving different social segments.}

\section{Abstract}

Based on the empirical research conducted in the last two years (built not only from the collection, selection and analysis of materials aired in traditional press and material posted on social networks, but also field observations and semi-structured interviews with the actors), we try to reflect on the social challenges placed by the music played in the hybrid and public spaces of the city of Rio de Janeiro, that is, seeking to rethink not only what factors determine the meanings assigned to the contact zones that are generated by balls and concerts performed in certain areas of the metropolis, but also the extent to which these musical events that provide joints and tensions between groups from different social - are, in a way, assisting in the daily construction of an intercultural citizenship.

\section{Keywords}

Communication, Music, City, Territorialities.

\section{No se puede jugar aquí!?}

Territorialidades sónicas-musicales en

Rio de Janeiro que producen tensiones y aproximaciones involucrando diferentes segmentos sociales

\section{Resumen}

Con base en la investigación empírica realizada en los últimos dos años (construido no sólo de la recogida, selección y análisis de los materiales transmitidos en los medios impresos tradicionales y material publicado en las redes sociales, sino también observaciones de campo y entrevistas seme-estructuradas con los actores) tiene por objeto reflexionar sobre los retos sociales de la música que se reproduce en el espacio híbrido y público de la ciudad de Río de Janeiro. Es decir, hemos buscado repensar no sólo qué factores determinan los significados asignados a las zonas de contacto que se generan en las rodas, bailes y conciertos realizados en ciertas áreas de la metrópolis, sino también el grado en que estos eventos musicales -que proporcionan condiciones para articulaciones y tensiones entre actores de diferentes segmentos sociales- posibilita, en cierto modo, subsidiar la construcción en el cotidiano de una ciudadanía intercultural.

\section{Palabras clave}

Comunicación, Música, Ciudad, Territorialidades. 


\section{Expediente}

A revista E-Compós é a publicação científica em formato eletrônico da Associação Nacional dos Programas de Pós-Graduação em Comunicação (Compós). Lançada em 2004, tem como principal finalidade difundir a produção acadêmica de pesquisadores da área de Comunicação, inseridos em instituições do Brasil e do exterior.

\section{E-COMPÓS I www.e-compos.org.br I E-ISSN 1808-2599}

Revista da Associação Nacional dos Programas de Pós-Graduação em Comunicação. Brasília, v.18, n.2, maio/ago. 2015. A identificação das edições, a partir de 2008, passa a ser volume anual com três números. Indexada por Latindex I www.latindex.unam.mx

\section{CONSELHO EDITORIAL}

Alexandre Rocha da Silva, Universidade Federal do Rio Grande do Sul, Brasil Alexandre Farbiarz, Universidade Federal Fluminense, Brasil Ana Carolina Damboriarena Escosteguy, Pontifícia Universidade Católica do Rio Grande do Sul, Brasil

Ana Carolina Rocha Pessôa Temer, Universidade Federal de Goiás, Brasil Ana Regina Barros Rego Leal, Universidade Federal do Piauí, Brasil André Luiz Martins Lemos, Universidade Federal da Bahia, Brasil Andrea França, Pontifícia Universidade Católica do Rio de Janeiro, Brasil Antonio Carlos Hohlfeldt, Pontifícia Universidade Católica do Rio Grande do Sul, Brasil

Arthur Ituassu, Pontifícia Universidade Católica do Rio de Janeiro, Brasil Álvaro Larangeira, Universidade Tuiuti do Paraná, Brasil Ângela Freire Prysthon, Universidade Federal de Pernambuco, Brasil César Geraldo Guimarães, Universidade Federal de Minas Gerais, Brasil Cláudio Novaes Pinto Coelho, Faculdade Cásper Líbero, Brasil Daisi Irmgard Vogel, Universidade Federal de Santa Catarina, Brasil Daniela Zanetti, Universidade Federal do Espírito Santo, Brasil Denize Correa Araujo, Universidade Tuiuti do Paraná, Brasil Eduardo Antonio de Jesus, Pontifícia Universidade Católica de Minas Gerais, Brasil

Eduardo Vicente, Universidade de São Paulo, Brasil

Elizabeth Moraes Gonçalves, Universidade Metodista de São Paulo, Brasil Erick Felinto de Oliveira, Universidade do Estado do Rio de Janeiro, Brasil Francisco Elinaldo Teixeira, Universidade Estadual de Campinas, Brasil Francisco Paulo Jamil Almeida Marques, Universidade Federal do Ceará, Brasil Gabriela Reinaldo, Universidade Federal do Ceará, Brasil Gisela Grangeiro da Silva Castro, Escola Superior de Propaganda e Marketing, Brasil

Goiamérico Felício Carneiro Santos, Universidade Federal de Goiás, Brasil Gustavo Daudt Fischer, Unisinos, Brasil

Herom Vargas, Universidade Municipal de São Caetano do Sul, Brasil
Itania Maria Mota Gomes, Universidade Federal da Bahia, Brasil Janice Caiafa, Universidade Federal do Rio de Janeiro, Brasil Jiani Adriana Bonin, Universidade do Vale do Rio dos Sinos, Brasil José Afonso da Silva Junior, Universidade Federal de Pernambuco, Brasil José Luiz Aidar Prado, Pontifícia Universidade Católica de São Paulo, Brasil Kati Caetano, Universidade Tuiuti do Paraná, Brasil

Lilian Cristina Monteiro França, Universidade Federal de Sergipe, Brasil

Liziane Soares Guazina, Universidade de Brasília, Brasil Luíza Mônica Assis da Silva, Universidade de Caxias do Sul, Brasil Luciana Miranda Costa, Universidade Federal do Pará, Brasil Malena Segura Contrera, Universidade Paulista, Brasil Marcel Vieira Barreto Silva, Universidade Federal da Paraíba, Brasil Maria Ogécia Drigo, Universidade de Sorocaba, Brasil Maria Ataide Malcher, Universidade Federal do Pará, Brasil Maria Clotilde Perez Rodrigues, Universidade de São Paulo, Brasil Maria das Graças Pinto Coelho, Universidade Federal do Rio Grande do Norte, Brasil

Mauricio Ribeiro da Silva, Universidade Paulista, Brasil

Mauro de Souza Ventura, Universidade Estadual Paulista, Brasil

Márcio Souza Gonçalves, Universidade do Estado do Rio de Janeiro, Brasil Micael Maiolino Herschmann, Universidade Federal do Rio de Janeiro, Brasil Mirna Feitoza Pereira, Universidade Federal do Amazonas, Brasil Nísia Martins Rosario, Universidade Federal do Rio Grande do Sul, Brasil Potiguara Mendes Silveira Jr, Universidade Federal de Juiz de Fora, Brasil Regiane Ribeiro, Universidade Federal do Paraná, Brasil Rogério Ferraraz, Universidade Anhembi Morumbi, Brasil Rose Melo Rocha, Escola Superior de Propaganda e Marketing, Brasil Rozinaldo Antonio Miani, Universidade Estadual de Londrina, Brasil Sérgio Luiz Gadini, Universidade Estadual de Ponta Grossa, Brasil Simone Maria Andrade Pereira de Sá, Universidade Federal Fluminense, Brasil Veneza Mayora Ronsini, Universidade Federal de Santa Maria, Brasil Walmir Albuquerque Barbosa, Universidade Federal do Amazonas, Brasil

\section{COMISSÃO EDITORIAL}

\section{Cristiane Freitas Gutfreind}

Pontifícia Universidade Católica do Rio Grande do Sul, Brasil

\section{Irene Machado}

Universidade de São Paulo, Brasil

Jorge Cardoso Filho

Universidade Federal do Reconcavo da Bahia, Brasil

Universidade Federal da Bahia, Brasil

\section{EQUIPE TÉCNICA}

ASSISTENTE EDITORIAL I Márcio Zanetti Negrini

REVISÃO DE TEXTOS I Press Revisão

EDITORAÇÃO ELETRÔNICA I Roka Estúdio

CONTATO I revistaecompos@gmail.com
COMPóS I www.compos.org.br

Associação Nacional dos Programas de Pós-Graduação em Comunicação

Presidente

Edson Fernando Dalmonte

Programa de Pós-Graduação em Comunicação

e Cultura Contemporânea - UFBA

edsondalmonte@uol.com.br

Vice-presidente

Cristiane Freitas Gutfreind

Programa de Pós-Graduação em Comunicação Social - PUC-RS cristianefreitas@pucrs.br

Secretário-Geral

Rogério Ferraraz

Programa de Pós-Graduação em Comunicação

Universidade Anhembi Morumbi

rogerioferraraz@anhembimorumbi.edu.br 